\title{
Isolation of Bacillus subtilis SJ4 from Saeu (Shrimp) Jeotgal, a Korean Fermented Seafood, and Its Fibrinolytic Activity
}

\author{
Zhuang Yao ${ }^{1}$, Yu Meng ${ }^{1}$, Huong Giang Le ${ }^{1}$, Jeong A Kim ${ }^{2}$, and Jeong Hwan Kim ${ }^{1,2 *}$ \\ ${ }^{1}$ Division of Applied Life Science (BK21 plus), Graduate School, ${ }^{2}$ Institute of Agriculture and Life Science, Gyeongsang National University, \\ Jinju 52828, Republic of Korea
}

Received: June 10, 2019 / Revised: July 6, 2019 / Accepted: July 10, 2019

\begin{abstract}
A Bacillus strain, SJ4, exhibiting strong fibrinolytic activity was isolated from saeu (shrimp, Acetes chinensis) jeotgal, a Korean traditional fermented food and was identified as B. subtilis. The B. subtilis SJ4 strain can grow at a $\mathrm{NaCl}$ concentration of up to $15 \%(\mathrm{w} / \mathrm{v})$. The fibrinolytic activity of $B$. subtilis $\mathrm{SJ} 4$ (152.0 U/ml) cultured in Luria-Bertani (LB) broth for $48 \mathrm{~h}$ at $37^{\circ} \mathrm{C}$ with aeration was higher than that of $B$. subtilis $\mathrm{SJ} 4$ cultured in TSB (124.5 U/ml) under same culture conditions. The major proteins in the LB culture supernatant of $B$. subtilis SJ4 were analyzed by SDS-PAGE, which revealed three major bands $(23,25$, and $28 \mathrm{kDa})$. The band $(23 \mathrm{kDa})$ with strong fibrinolytic activity, analyzed on fibrin zymogram, was observed at 60-96 $\mathrm{h}$ of cultivation. The aprESJ4 gene encoding the major fibrinolytic enzyme, AprESJ4, was cloned by PCR. The aprESJ4 gene sequence exhibited high similarities with the fibrinolytic gene sequences of other Bacillus species. The amino acid sequence of AprESJ4 exhibited 98.9 and 98.4\% similarity with subtilisin NAT and AprE2 of $B$. subtilis, respectively. Hence, B. subtilis $\mathbf{S J} 4$ can be a potential starter culture for jeotgal products.
\end{abstract}

Keywords: Bacillus subtilis, saeu jeotgal, fibrinolytic enzyme, starter, aprESJ4

\section{Introduction}

Bacillus subtilis is one of the most industrially important microorganisms, and used as a host for producing enzymes such as amylases and proteases $[1,2]$. B. subtilis is also well-known as a producer of various antimicrobial substances including bacteriocins and lipopeptides [3]. B. subtilis has served as a model organism representing gram-positive bacteria and spore forming bacteria. $B$. subtilis and closely related Bacillus species have been used for fermented soyfoods such as doenjang, meju, douchi, miso, and tempeh in Asian countries including Korea, China, Japan, and Indonesia. They are also

\section{*Corresponding author}

Tel: +82-55-772-1904, Fax: +82-55-772-1909

E-mail: jeonghkm@gnu.ac.kr

๑) 2019, The Korean Society for Microbiology and Biotechnology actively utilized as probiotics for human and animals [4, 5]. Isolation of B. subtilis strains with useful properties are important because such strains can be used to improve current production processes for metabolites or to develop new processes if isolates produce some novel products with commercial values [6].

We screened jeotgals, Korean traditional fermented seafoods, to isolate Bacillus species with useful properties. Since marine environments are different from terrestrial environments, some bacilli from jeotgals were expected to possess some novel and useful properties [6]. Among the bacilli isolates, one strain (SJ4) showed strong fibrinolytic activity together with antibacterial activity. SJ4 was identified as B. subtilis and its fibrinolytic activity was studied in details. Some B. subtilis strains are known to produce a strong fibrinolytic enzyme known as "Nattokinase". Nattokinase can dis- 
solve fibrin clots in vitro and is believed to play the same function in human body [7]. Products containing Nattokinase are sold as health supplements to prevent or treat vascular diseases caused by fibrin accumulation in blood vessels [8]. Other Bacillus species closely related to $B$. subtilis also secrete fibrinolytic enzymes with similar properties [9-11]. Nattokinase and closely related fibrinolytic enzymes are functional materials with potentials as functional food ingredients and medicines replacing current thrombolytic agents such as streptokinase, urokinase, or t-PA (tissue plasminogen activator). More studies are desirable for the production of functional foods and bioactive ingredients from Bacillus species isolated from marine environments. In this respect, B. subtilis SJ4, as a GRAS organism, seems useful as a starter for fermented soyfoods and jeotgals considering its strong fibrinolytic and antimicrobial activities in addition to its significant salt tolerance.

\section{Materials and Methods}

Isolation and identification of Bacillus strains from jeotgal

Three different types of jeotgals, saeu (shrimp, Acetes chinensis), myeolchi (anchovy, Engraulis japonicus) and hwangseok-eo (big head croaker, Colichthys lucidus) jeotgals, were purchased at a local market of Jinju, Gyeongnam, Korea, in during the Spring of 2019. Ten grams of each jeotgal was mixed with $90 \mathrm{ml}$ of sterile $0.1 \%$ peptone water and homogenized using a stomacher (Seward, UK). The homogenate was serially diluted using $0.1 \%$ peptone water. Aliquots $(0.1 \mathrm{ml})$ of diluted samples were spread onto Luria-Bertani (LB) agar plates (tryptone $10 \mathrm{~g}$, yeast extract $5 \mathrm{~g}, \mathrm{NaCl} 5 \mathrm{~g}$, per liter, $\mathrm{pH} 7.0$ ) and the plates were incubated at $37^{\circ} \mathrm{C}$ until colonies appeared.

Colonies showing typical Bacillus morphology were selected and spotted onto LB agar plates with skim milk $(1 \%, w / v)$, and the plates were incubated at $37^{\circ} \mathrm{C}$. Colonies showing large lysis zones were selected and their fibrinolytic activities were examined by spotting on fibrin plates as described previously [9].

For identification of Bacillus sp. SJ4, 16S rRNA genes were amplified using primers: bac-F (5'-CGGCGTGCCTAATACATGCAAG-3') and bac-R (5'-GGCATGCTGATCCGCATTACTA-3') [12]. A recA gene was amplified using the following primers: recA-F (5'-TGAGTGATC-
GTCAGGCAGCCTTAG-3') and recA-R (5'-CYTBRGATAAGAR TACCAWGMACCGC-3') [12]. Amplification was done using a thermocycler (MJ Mini personal thermal cycler, BioRad, USA). The reaction mixture (50 $\mu \mathrm{l})$ contained $2 \mu \mathrm{l}$ of template DNA, $2 \mu \mathrm{l}$ of each primer $(10 \mu \mathrm{M}), 5 \mu \mathrm{l}$ of dNTPs $(0.25 \mathrm{mM})$, and $0.5 \mu \mathrm{l}$ of ExTaq DNA polymerase (Takara, Japan). Amplification conditions were as follows: initial denaturation at $94^{\circ} \mathrm{C}$ for $5 \mathrm{~min}$ followed by 30 cycles of $94^{\circ} \mathrm{C}$ for $30 \mathrm{~s}, 58^{\circ} \mathrm{C}$ for $30 \mathrm{~s}$, $72^{\circ} \mathrm{C}$ for $40 \mathrm{~s}$, and a final extension at $72^{\circ} \mathrm{C}$ for $5 \mathrm{~min}$. Chromosomal DNA was prepared from culture grown in LB broth for $18 \mathrm{~h}$ by using a phenol-chloroform extraction method [12]. Nucleotide sequences of the amplified fragments were determined at Cosmogenetech (Korea). BLAST program (National Center for Biotechnology Information) was used to find homologous sequences in the data library (http://www.ncbi.nlm.nih.gov).

\section{Growth and fibrinolytic activity of B. subtilis SJ4 in different culture media}

B. subtilis SJ4 was cultivated in 4 different media: LB broth, brain heart infusion broth (BHI, Becton, Dickinson and Company, USA), nutrient broth (NB, Becton, Dickinson and Company), and tryptic soy broth (TSB, Becton, Dickinson and Company). Aliquots were taken at $12 \mathrm{~h}$ intervals during $96 \mathrm{~h}$ cultivation at $37^{\circ} \mathrm{C}$ with shaking, and $\mathrm{OD}_{600}$ values were measured (UV1601, Shimadzu, Japan). An aliquot of the culture was centrifuged at $4,000 \times g$ for $10 \mathrm{~min}$ at $4{ }^{\circ} \mathrm{C}$, and the supernatant was filtered using $0.45 \mu \mathrm{m}$ filter (Sartorius Stedim, Germany). The filtered supernatant (FS) was used for fibrinolytic activity measurement by fibrin plate method [9]. The size of a lysis zone on a fibrin plate was measured and converted into a plasmin unit (U) by comparing its size with those formed by plasmin (Sigma) at different units. All measurements were done in triplicates and the mean values were used.

\section{Salt tolerance of B. subtilis SJ4}

Salt tolerance of B. subtilis SJ4 was studied. B. subtilis SJ4 was inoculated (1\%, v/v) into TSB with 5, 8, 10, 12, 15 , and $18 \%(\mathrm{w} / \mathrm{v}) \mathrm{NaCl}$, and incubated for $96 \mathrm{~h}$ at $37^{\circ} \mathrm{C}$ with aeration. Aliquots of cultures were taken at $12 \mathrm{~h}$ intervals, and the growth was checked by measuring the absorbance at $600 \mathrm{~nm}$. All measurements were done in triplicates and the mean values were used. 


\section{SDS-PAGE and fibrin zymography}

FS was prepared from $B$. subtilis SJ4 culture grown for $96 \mathrm{~h}$ in LB broth, and analyzed by SDS-PAGE. A 10\% acrylamide gel was used and $20 \mu \mathrm{g}$ of FS was loaded after being boiled for $5 \mathrm{~min}$ in $4 \times$ SDS sample buffer. Fibrin zymography was done using a polyacryamide gel containing fibrin, which was prepared by mixing fibrinogen $(0.1 \%, \mathrm{w} / \mathrm{v})$ and $100 \mu \mathrm{l}$ of thrombin $(1,000 \mathrm{NIH}$ units/ $\mathrm{ml}$ ) with acrylamide solution. After electrophoresis at a constant current of $10 \mathrm{~mA}$ on ice, the fibrin gel was soaked in $50 \mathrm{mM}$ Tris-HCl ( $\mathrm{pH}$ 7.4) buffer containing $2.5 \%$ Triton X-100 for $30 \mathrm{~min}$ at room temperature on a rotary shaker. The gel was then washed with distilled water for 30 min to remove the Triton X-100 and soaked in zymogram reaction buffer $(30 \mathrm{mM}$ Tris- $\mathrm{HCl}, \mathrm{pH} 7.4$, and $0.02 \%$ of $\mathrm{NaN}_{3}$ ) for $12 \mathrm{~h}$ at $37^{\circ} \mathrm{C}$. Finally, the gel was stained with coomassie blue R-250.

\section{Cloning of the aprESJ4 gene}

The major fibrinolytic enzyme gene, aprESJ4, was cloned from B. subtilis SJ4 genome by PCR. A primer pair was used, CH51-F (5'-A GATTGCGGCTGTGTAC-3', BamHI site underlined) and CH51-R (5'-AGAATTCTTCAGAGGGAGCCACCCGTC GATCA-3', EcoRI site underlined) [13]. PCR reaction mixture $(50 \mu \mathrm{l})$ contained $2 \mu \mathrm{l}$ of template DNA, $2 \mu \mathrm{l}$ of each primer $(10 \mu \mathrm{M}), 5 \mu \mathrm{l}$ of dNTPs $(0.25 \mathrm{mM})$, and $0.5 \mu \mathrm{l}$ of ExTaq DNA polymerase (Takara). The amplification conditions were as follows: $94^{\circ} \mathrm{C}$ for $5 \mathrm{~min}$; 30 cycles of $94^{\circ} \mathrm{C}$ for $30 \mathrm{~s}, 58^{\circ} \mathrm{C}$ for $30 \mathrm{~s}, 72^{\circ} \mathrm{C}$ for $40 \mathrm{~s}$; a final extension at $72^{\circ} \mathrm{C}$ for $4 \mathrm{~min}$. The amplified fragment was ligated into pGEM-T Easy Vector (Promega, USA) and E. coli DH5 $\alpha$ competent cells (Enzynomics, Korea) were transformed with the ligation mixture. Plasmid DNA was prepared by using a kit (iNtRON Biotech., Korea). DNA sequencing and BLAST analyses were done as described previously.

\section{Results and Discussion}

\section{Isolation and identification of Bacillus sp. SJ4}

One bacilli isolate, SJ4, was obtained from saeu jeotgal. It was gram-positive, rod-typed, and the colony showed a typical Bacillus morphology on LB agar plates. Bacillus sp. SJ4 showed strong protease and fibrinolytic activities together with antimicrobial activ- ity. Total DNA was prepared and 16S rRNA and recA genes were amplified and sequenced. BLAST analyses showed that 16S rRNA gene sequence (1,179 nucleotides, MK648141) of Bacillus sp. SJ4 showed 99\% identities to those from B. amyloliquefaciens, B. velezensis, B. subtilis, and B. siamensis. Partial recA gene (772 nucleotides, MK648143) sequence showed 99\% identities to those from B. subtilis strains. From these results, Bacillus sp. SJ4 was positively identified as B. subtilis, and named accordingly $B$. subtilis SJ4.

\section{Growth and fibrinolytic activity of $B$. subtilis SJ4 in different culture media}

B. subtilis SJ4 grew well in LB, BHI, and TSB media,
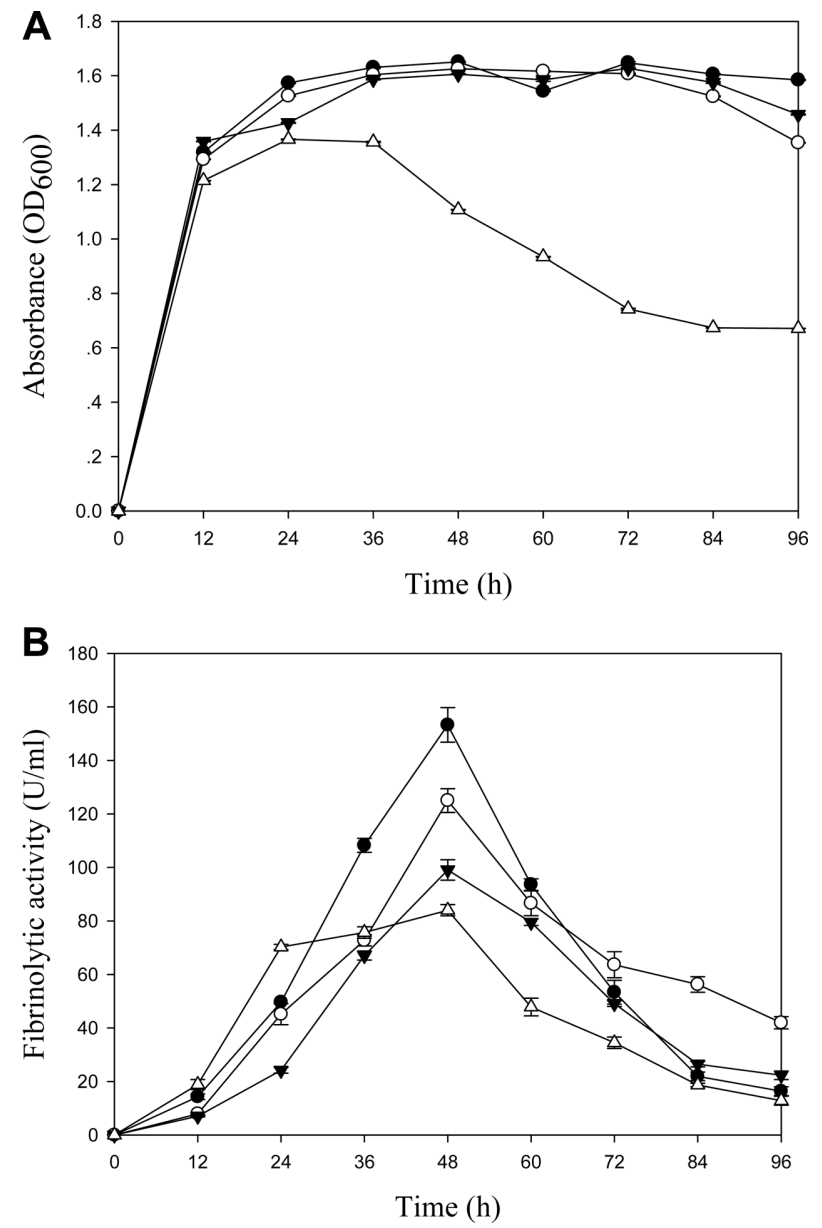

Fig. 1. Observation of B. subtilis SJ4 (A) growth and (B) fibrinolytic activity in different culture media. - - , LB; - $O-$, TSB; $-\nabla-, B H I ;-\triangle-$, NB. FS at each time point was applied to a fibrin plate and the fibrinolytic activity was expressed as $\mathrm{U} / \mathrm{ml}$. Plasmin $(4,8,16$, and $60 \mathrm{mU})$ was used as the standard. 
showing similar growth curves in these 3 culture media. The $\mathrm{OD}_{600}$ values reached $1.43-1.57$ at $24 \mathrm{~h}$, and gradually increased to $1.61-1.65$ at $48 \mathrm{~h}$ (Fig. 1A). The final values were $1.35-1.58$ at $96 \mathrm{~h}$. In contrast, the $\mathrm{OD}_{600}$ value of $\mathrm{NB}$ culture reached 1.37 at $24 \mathrm{~h}$ and then decreased continuously. The final value at $96 \mathrm{~h}$ was 0.67 , which was significantly lower than those of other cultures. The highest fibrinolytic activity, $152.0 \mathrm{U} / \mathrm{ml}$, was observed from culture in LB at $48 \mathrm{~h}$ followed by culture in TSB (124.5 U/ml) at the same time point. Culture in BHI showed $97.5 \mathrm{U} / \mathrm{ml}$ and culture in $\mathrm{NB}$ showed the lowest activity $(84.3 \mathrm{U} / \mathrm{ml})$ at $48 \mathrm{~h}$. After $48 \mathrm{~h}$, fibrinolytic activities decreased continuously in all cultures.

Changes in fibrinolytic activities during growth are variable depending upon hosts. Like $B$. subtilis SJ4, $B$. amyloliquefaciens RSB34 isolated from doenjang (a Korean fermented soyfood) showed the highest activity at $48 \mathrm{~h}$ when grown in LB [9]. In contrast, other Bacillus isolates showed the highest enzyme activities at $96 \mathrm{~h}$ or later during cultivation $[14,15]$. The activity profile is also variable depending upon culture medium as shown in this work.

\section{Salt tolerance of B. subtilis SJ4}

B. subtilis $\mathrm{SJ} 4$ can grow well in TSB with $\mathrm{NaCl}$ up to $12 \%$ (w/v). Culture with $5-12 \% \mathrm{NaCl}$ reached the highest $\mathrm{OD}_{600}$ values of $1.50-1.68$ at $48 \mathrm{~h}$ and then decreased gradually. It took $12 \mathrm{~h}$ for B. subtilis SJ4 to start to grow rapidly at $12 \% \mathrm{NaCl}$ (Fig. 2). At $15 \% \mathrm{NaCl}$,

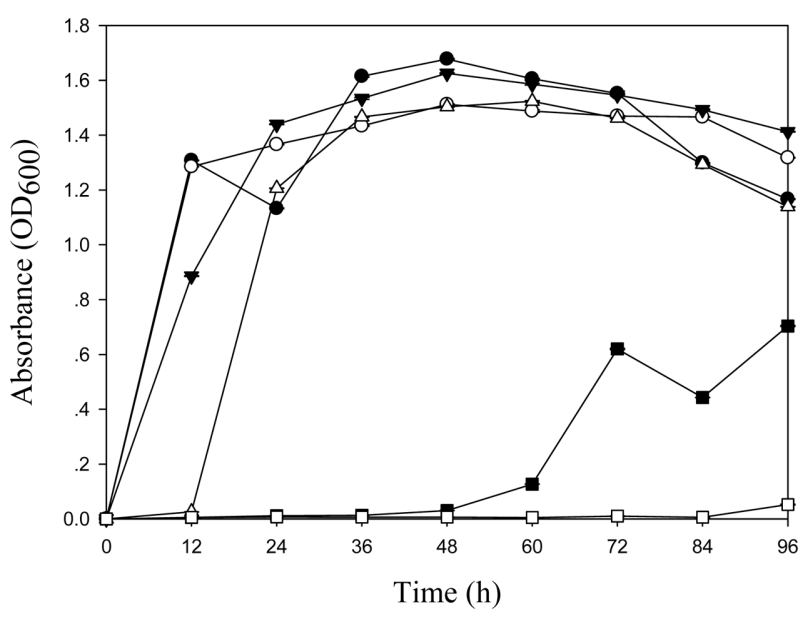

Fig. 2. Growth of B. subtilis SJ4 in TSB with $\mathrm{NaCl}(5-18 \%$, w/v). $-\bullet-, 5 \% ;-\bigcirc-, 8 \% ;-\nabla-, 10 \% ;-\triangle-, 12 \% ;-\square-, 15 \%$; - -, $18 \% \mathrm{NaCl}$. it took $48 \mathrm{~h}$ before $B$. subtilis $\mathrm{SJ} 4$ started to grow but the $\mathrm{OD}_{600}$ value was 0.70 at $96 \mathrm{~h}$, quite lower than the cultures with 5-12\% $\mathrm{NaCl}$ (1.14-1.17 at 96 h). B. subtilis SJ4 could not grow at $18 \% \mathrm{NaCl}$ concentration. Considering its significant salt tolerance, B. subtilis SJ4 can be used as a starter for fermented foods such as jeotgals where the salt concentration does not exceed 15\%. B. subtilis SJ4 produced antimicrobial substances against some food pathogens such as $B$. cereus (results not shown). These days, consumers prefer foods with less salt because high salt diet is known to cause several serious health problems [16]. For this, fermented foods such as soy paste, soy sauce, and jeotgals are produced with reduced salt contents compared to traditional fermented foods where lots of salts are added to prevent putrefaction by spoilage bacteria during fermentation. Growth of pathogenic bacteria is a serious problem for low salt foods. Use of Bacillus strains with antimicrobial activity as starters can reduce the risk of bacterial contamination.

\section{SDS-PAGE and fibrin zymography}

FS samples from culture grown for $96 \mathrm{~h}$ in LB were analyzed by SDS-PAGE (Fig. 3A). Three proteins, 23, 25, and $28 \mathrm{kDa}$ in size, were the major bands on a coomassie stained gel. Minor bands of ca 42 and $58 \mathrm{kDa}$ in size were also observed (Fig. 3A). The intensity of the 23, 25, and $28 \mathrm{kDa}$ bands reached the highest around $60 \mathrm{~h}$. On a zymogram gel loaded with the same samples, $23 \mathrm{kDa}$ band was clearly observed among samples collected from 60-96 h time points (Fig. 3B). Faint band of ca $42 \mathrm{kDa}$ was also observed on the zymogram, and the band intensity increased around $60 \mathrm{~h}$ although it appeared at $36 \mathrm{~h}$ of incubation.

Considering the size of reported fibrinolytic enzymes, the $28 \mathrm{kDa}$ band seems as the major fibrinolytic protein in B. subtilis SJ4. The fibrin zymogram results were different from the fibrinolytic activity measurement results (Fig. 1) where the highest activity was observed at $48 \mathrm{~h}$. Also, the band intensity of $28 \mathrm{kDa}$ protein was higher at $60 \mathrm{~h}$ on a zymogram. The $23 \mathrm{kDa}$ band showing strong fibrinolytic activity on a zymogram appeared around $60 \mathrm{~h}$ and similar intensity was maintained until $96 \mathrm{~h}$. The intensity of $23 \mathrm{kDa}$ band seemed at the highest at 72 h. A growth stage, at which the highest fibrinolytic activity was observed, was usually the time point where 


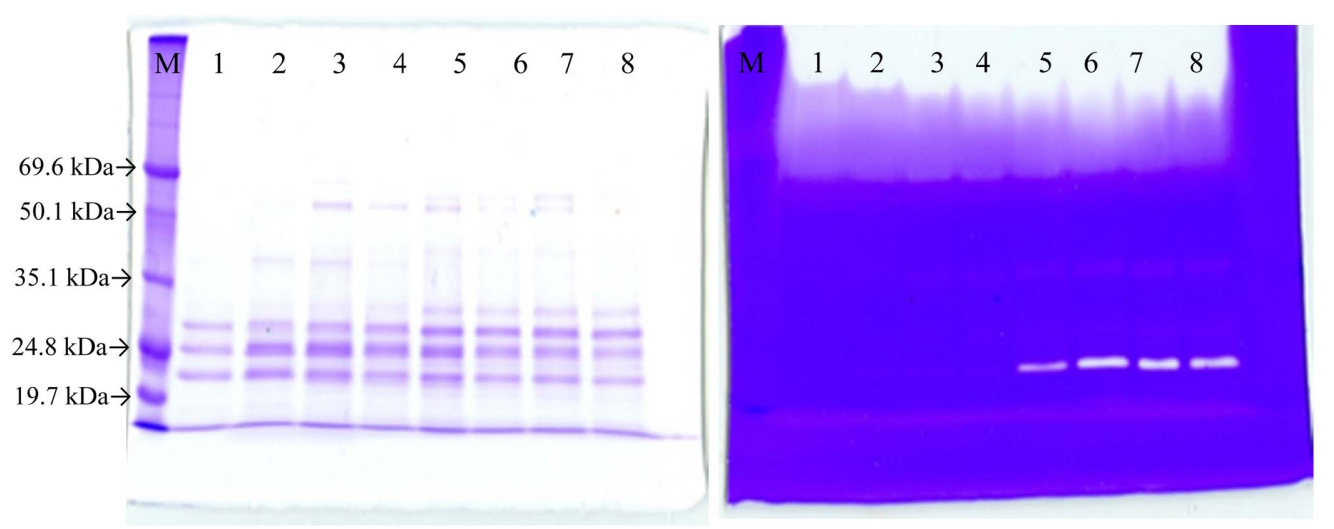

Fig. 3. Analysis of FS from B. subtilis SJ4 using (A) coomassie blue stained gel and (B) fibrin zymogram. M, Dokdo-marker broad-range (EBM-1034, Elpis-Biotech., Daejeon, Korea). B. subtilis SJ4 was grown in LB broth for $96 \mathrm{~h}$ at $37^{\circ} \mathrm{C} .1,12 \mathrm{~h} ; 2,24 \mathrm{~h} ; 3,36$ h; 4, 48 h; 5.60 h; 6, 72 h; 7, 84 h; 8, 96 h.

the intensity of the $27 \mathrm{kDa}$ protein was the highest on a fibrin zymogram $[13,14]$. It is not known why the highest fibrinolytic activity of $B$. subtilis $\mathrm{SJ} 4$ culture was observed at $48 \mathrm{~h}$ but at that time point, intensity of the
$27 \mathrm{kDa}$ band was not at the highest. Purification and characterization of fibrinolytic enzymes are necessary to better understand the fibrinolytic enzymes in B. subtilis SJ4.

\begin{tabular}{|c|c|}
\hline & \\
\hline & \\
\hline & \\
\hline 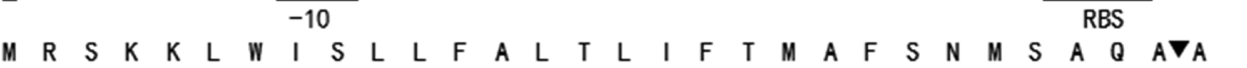 & \\
\hline GAGAAGCAAAAAAT TGTGGATCAGCT TGTTGTTTGCGT TAACGT TAATCT TTACGATGGCGT TCAGCAACATGTCTGCGCAGGCTGC & \\
\hline $\begin{array}{llllllllllllllllllllllllllllll}K & S & S & T & E & K & K & Y & I & V & G & F & K & G & T & M & S & A & M & S & S & A & K & K & K & D & V & I & S\end{array}$ & \\
\hline GAAAAAGCAGTACAGAAAAGAAATACATTGTCGGATTTAAACAGACAATGAGTGCCATGAGTTCCGCCAAGAAAAAGGATGTTATTTCT & 45 \\
\hline 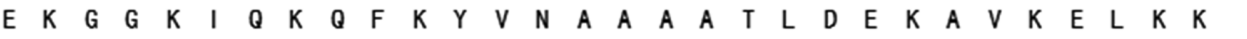 & \\
\hline & \\
\hline 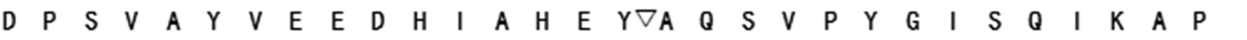 & \\
\hline ATCCGAGCGTTGCATATGTGGAAGAAGATCATATTGCACATGAATATGCGCAATCTGTTCCTTATGGCATTTCTCAAATTAAAGCGCC & \\
\hline 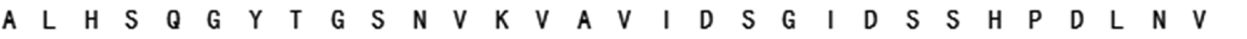 & \\
\hline СTCTTCACTCTCAAGGCTACACAGGCTCTAACGTAAAAGTAGCTGTTATCGACAGCGGAAT TGACTCTTCTCATCCTGACT TAAACGTC & \\
\hline 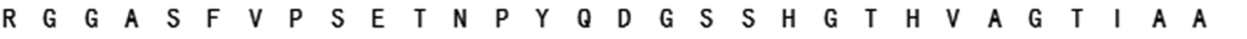 & \\
\hline GAGGCGGAGCAAGCT TCGTACCT TCTGAAACAAACCCATACCAGGACGGCAGTTCTCACGGTACGCATGTAGCCGGTACGATTGCCGCT & \\
\hline 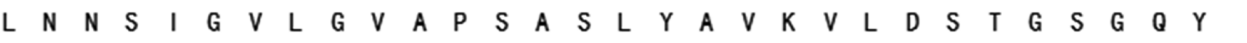 & \\
\hline TTAATAACTCCATCGGTGTTCTGGGCGTAGCGCCAAGCGCATCAT TATATGCAGTAAAAGTGCTTGATTCAACAGGAAGCGGCCAATAT & \\
\hline 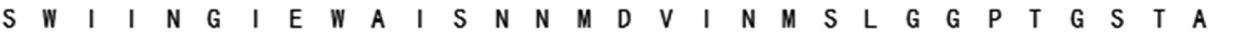 & \\
\hline GCTGGATTATTAACGGCAT TGAGTGGGCCAT TTCCAACAATATGGATGTTATCAACATGAGCCTTGGCGGACCTACTGGTTCTACAGCG & \\
\hline 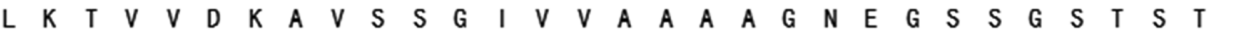 & \\
\hline TGAAAACAGTAGT TGATAAAGCGGTTTCCAGCGGTATCGTCGTTGCTGCCGCAGCCGGAAACGAAGGTTCGTCCGGAAGCACAAGCACA & 1080 \\
\hline 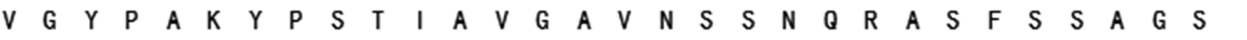 & \\
\hline TCGGCTACCCTGCAAAATATCCT TCTACTAT TGCAGTAGGTGCGGTAAACAGCAGCAACCAAAGAGCTTCATTCTCCAGCGCAGGTTCT & 17 \\
\hline 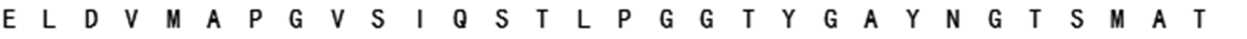 & 3 \\
\hline AGCTTGATGTAATGGCTCCTGGCGTGTCCATCCAAAGCACACTTCCTGGAGGCACTTACGGCGCTTATAACGGAACGTCCATGGCGACT & 26 \\
\hline 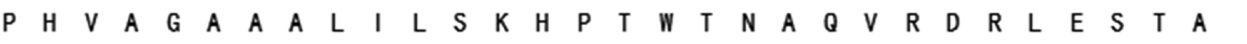 & 360 \\
\hline CTCACGT TGCCGGAGCAGCAGCGCTAATTCT TTCTAAGCACCCGACT TGGACAAATGCGCAAGTCCGTGATCGTTTAGAAAGCACTGCA & \\
\hline 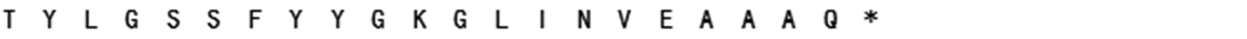 & \\
\hline & \\
\hline АCCTGCTTCT TTITATTTGCCCGCATCCTGTTCTGTGGCAGGATGT TCCGGTGCATCCCCT & \\
\hline
\end{tabular}

Fig. 4. Nucleotide sequence of aprESJ4. The deduced amino acid sequences are shown below the nucleotide sequences. Putative -35 and -10 promoter sequences are underlined. Putative ribosome binding site (RBS) and transcription terminators are also underlined. The ends of pre $(\boldsymbol{\nabla})$ and pro sequences $(\nabla)$ are marked. The stop codon is marked as the asterisk above the nucleotide sequence. 


\section{Gene cloning of aprESJ4}

The major fibrinolytic gene of B. subtilis SJ4 was cloned by PCR using a primer pair which was initially used for the cloning of a homologous gene from $B$. amyloliquefaciens [13]. A $1.5 \mathrm{~kb}$ fragment was cloned into pGEM-T easy vector and sequenced. A total of 1,529 nucleotides were sequenced (Fig. 4) and analyzed by BLAST. The result confirmed that the cloned gene was indeed a homolog of aprE genes. The sequence was deposited in GenBank (Accession No. MK796246). An ORF of $1,146 \mathrm{bp}$ in size, capable of encoding a protein of 381 amino acids in length was found. The first 29 amino acids corresponded to a signal peptide as judged by
SignalP 4.1 Server (Technical University of Denmark) and the next 77 amino acids corresponded to prosequence as judged from comparison with other similar fibrinolytic enzymes. pI and size of proAprESJ4 (352 aa) were 7.98 and $36,164.37 \mathrm{Da}$, respectively. The first amino acid of the mature enzyme was suspected to be alanine $\left(108^{\text {th }}\right)$, and $\mathrm{pI}$ and size of the mature enzyme were 6.04 and 27,672.65 Da, respectively. Calculated size of mature enzyme matched well with the observed $28 \mathrm{kDa}$ band on coomassie stained gel (Fig. 3).

Nucleotide sequence of aprESJ4 showed high similarities with other fibrinolytic genes from $B$. subtilis CH3-5 [17], B. subtilis subsp. natto BEST195 [18], and

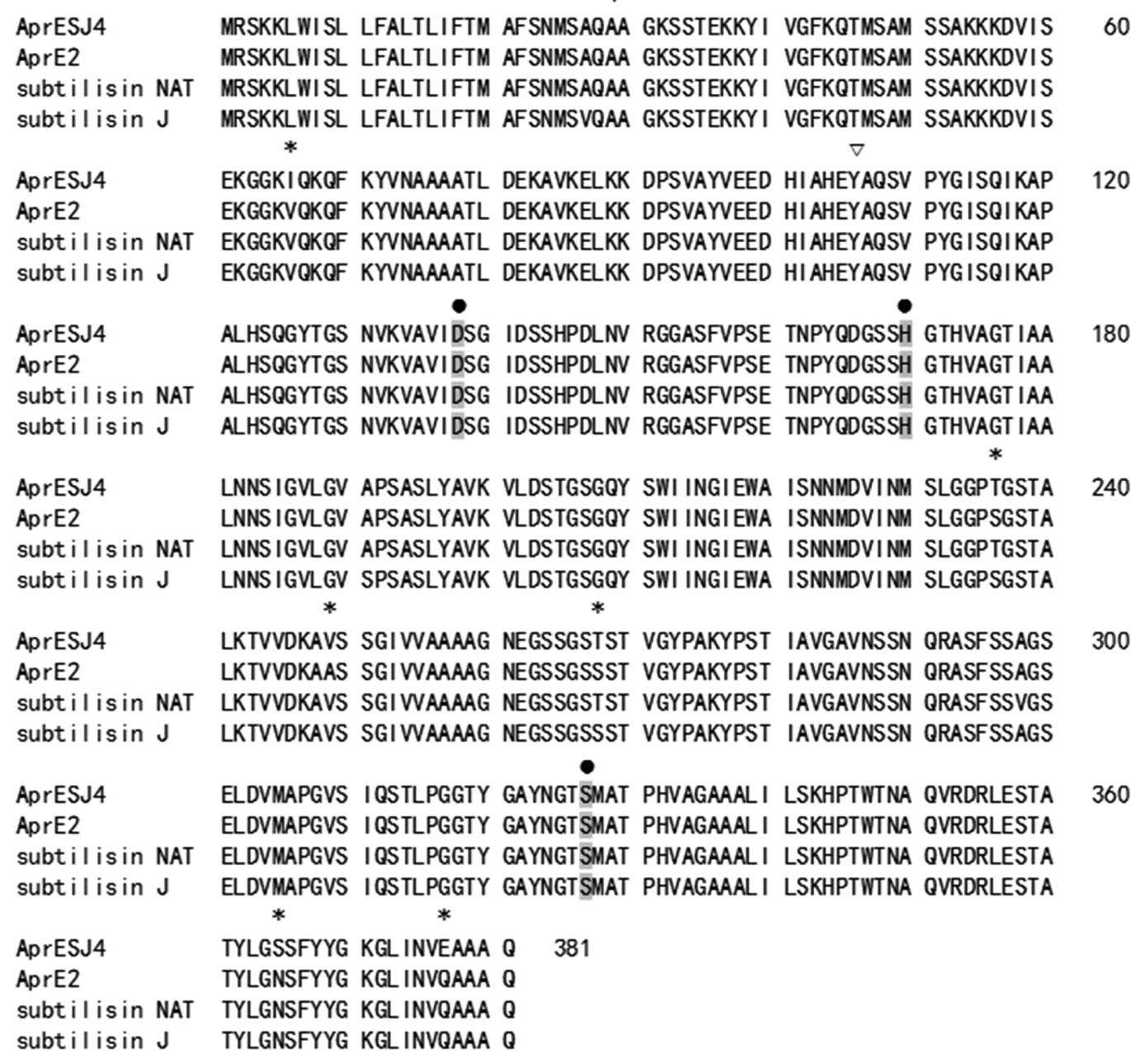

Fig. 5. Alignment of amino acid sequence of AprESJ4 with homologous enzymes from bacilli. AprE2 (B. subtilis CH3-5, ABJ98765), Subtilisin NAT (B. subtilis subsp. natto BEST195, AYK86398), and Subtilisin J (B. stearothermophilus NCIMB10278, AAA22247). Amino acids different from other enzymes are marked as asterisks (*) above the amino acids. The ends of pre ( $\boldsymbol{\nabla}$ ) and pro sequences $(\nabla)$ are marked. Three amino acids (D32, H64 and S221), constituting the conserved catalytic triad of fibrinolytic enzymes belonging to subtilisin family, are marked as solid circle $(\mathbf{O})$ above the amino acids. 
B. stearothermophilus NCIMB10278 [19]. Translated amino acid sequence of AprESJ4 was aligned with those of other homologous enzymes (Fig. 5). AprESJ4 showed 98.43\% identity with AprE2 (375/381) from B. subtilis CH3-5 (ABJ98765), 98.95\% with subtilisin NAT (377/ 381) from B. ubtilis ssp. natto BEST195 (AYK86398), and $98.16 \%$ with subtilisin $J$ (374/381) from $B$. stearothermophilus NCIMB10278 (AAA22247). Conserved amino acids (S221, H64, and D32) were also present in AprESJ4, which are important for catalytic activity, and present in almost all fibrinolytic enzymes [20]. Comparision of amino acid sequence of AprESJ4 with other fibrinolytic enzymes from bacilli indicated that these enzymes are highly conserved among bacilli regardless of their sources. B. subtilis SJ4, isolated from marine environments, secretes almost the same enzyme produced by bacilli from soil and plants. This signifies the importance of $a p r E$ genes for the survival of bacilli under various environments including marine environments.

B. subtilis SJ4 was isolated from saeu jeotgal, a fermented food prepared from saeu (small shrimp) and salt, and saeu jeotgal can be considered as a part of marine environments. Bacilli from marine environments are supposedly different from bacilli originated from terrestrial environments such as soil and plants [21, 22]. For this reason, efforts to isolate novel bacilli from marine environments have been made because they might produce novel metabolites useful for medicine and other bioindustries $[6,23]$. B. subtilis SJ4 can grow at the maximum salt concentration of $15 \%(\mathrm{w} / \mathrm{v})$, secrete fibrinolytic enzymes, and the strain possesses antibacterial activities (results not shown). Considering these facts, B. subtilis SJ4 and other bacilli from marine environments can be used as starters for salted fermented foods including jeotgals, and hosts for production of functional materials such as fibrinolytic enzymes. Further future studies are desirable for more detailed characterization of fibrinolytic enzymes from B. subtilis SJ4.

\section{Acknowledgments}

This work was supported by the Basic Science Research Program through the National Research Foundation of Korea (NRF) funded by the Ministry of Education (2017R1D1A1B03030037). Zhuang Yao, Meng Yu, and Jeong A Kim were supported by BK21 Plus program, MOE, Republic of Korea.

\section{Conflict of Interest}

The authors have no financial conflicts of interest to declare.

\section{References}

1. Schallmey M, Singh A, Ward OP. 2004. Developments in the use of Bacillus species for industrial production. Can. J. Microbiol. 50: 1-17.

2. Cui W, Han L, Suo F, Liu Z, Zhou L, Zhou Z. 2018. Exploitation of Bacillus subtilis as a robust workhorse for production of heterologous proteins and beyond. World J. Microbiol. Biotechnol. 34: 145.

3. Stein T. 2005. Bacillus subtilis antibiotics: structure, syntheses and specific functions. Mol. Microbiol. 56: 845-857.

4. Cutting SM. 2011. Bacillus probiotics. Food Microbiol. 28: 214220.

5. Elshaghabee FMF, Rokana N, Gulhane RD, Sharma C, Panwar H2017. Bacillus as potential probiotics: status, concerns, and future perspectives. Front. Microbiol. 8: 1490.

6. Mondol MA, Shin HJ, Islam MT. 2013. Diversity of secondary metabolites from marine Bacillus species: chemistry and biological activity. Mar. Drugs 11: 2846-2872.

7. Weng Y, Yao J, Sparks S, Wang KY. 2017. Nattokinase: an oral antithrombotic agents for the prevention of cardiovascular disease. Int. J. Mol. Sci. 18. pii: E523.

8. Dabbagh F, Negahdaripour M, Berenjian A, Behfar A, Mohammadi F, Zamani M, et al. 2014. Nattokinase: production and application. Appl. Microbiol. Biotechnol. 98: 9199-9206.

9. Yao Z, Liu X, Shim JM, Lee KW, Kim HJ, Kim JH. 2017. Properties of a fibrinolytic enzyme secreted by Bacillus amyloliquefaciens RSB34, isolated from doenjang. J. Microbiol. Biotechnol. 27: 9-18.

10. Peng Y, Huang Q, Zhang R, Zhang YZ. 2003. Purification and characterization of a fibrinolytic enzyme produced by Bacillus amyloliquefaciens DC-4 screened from douchi, a traditional Chinese soybean food. Comp. Biochem. Physiol. B. Biochem. Mol. Biol. 134: 45-52.

11. Jo HD, Kwon GH, Park JY, Cha J, Song YS, Kim JH. 2011. Cloning and overexpression of aprE3-17 encoding the major fibrinolytic protease of Bacillus licheniformis CH3-17. Biotechnol. Bioprocess Eng. 16: 352-359.

12. Kwon GH, Lee HA, Park JY, Kim JS, Lim JK, Park CS, et al. 2009. Development of a RAPD-PCR method for identification of Bacillus species isolated from cheonggukjang. Int. J. Food Microbiol. 129: 282-287.

13. Kim GM, Lee AR, Lee KW, Park JY, Chun J, Cha J, et al. 2009. Characterization of a $27 \mathrm{kDa}$ fibrinolytic enzyme from Bacillus amyloliquefaciens $\mathrm{CH} 51$ isolated from cheonggukjang. J. Microbiol. Biotechnol. 19: 997-1004.

14. Lee AR, Kim GM, Park JY, Jo HD, Cha J, Song YS, et al. 2010. Characterization of a $27 \mathrm{kDa}$ fibrinolytic enzyme from Bacillus amyloliquefaciens $\mathrm{CH} 86-1$ isolated from cheonggukjang. J. Korean Soc. Appl. Biol. Chem. 53: 56-61. 
15. Yao Z, Kim JA, Kim JH. 2018. Gene cloning, expression, and properties of a fibrinolytic enzyme secreted by Bacillus pumilus BS15 isolated from gul (oyster) jeotgal. Biotechnol. Bioprocess Eng. 23: 293-301.

16. Graudal N, Jürgens G. 2018. Conflicting evidence on health effects associated with salt reduction calls for a redesign of the salt dietary guidelines. Prog. Cardiovasc. Dis. 61: 20-26.

17. Jeong SJ, Kwon GH, Chun J, Kim JS, Park CS, Kwon DY, et al. 2007. Cloning of fibrinolytic enzyme gene from Bacillus subtilis isolated from Cheonggukjang and its expression in protease-deficient Bacillus subtilis strains J. Microbiol. Biotechnol. 17: 1018-1023.

18. Nakamura T, Yamagata Y, Ichishima E. 1992. Nucleotide sequence of the subtilisin NAT gene, aprN, of Bacillus subtilis (Natto). Biosci. Biotechnol. Biochem. 56: 1869-1871.

19. Jang JS, Kang DO, Chun MJ, Byun SM. 1992. Molecular cloning of a subtilisin J gene from Bacillus stearothermophilus and its expression in Bacillus subtilis. Biochem. Biophys. Res. Commun. 184: 277-282.

20. Peng Y, Yang X, Zhang Y. 2005. Microbial fibrinolytic enzymes: An overview of source, production, properties, and thrombolytic activity in vivo. Appl. Microbiol. Biotechnol. 69: 126-132.

21. Prieto ML, O'Sullivan L, Tan SP, McLoughlin P, Hughes H, Gutierrez $M$, et al. 2014. In vitro assessment of marine Bacillus for use as livestock probiotics. Mar. Drugs 12: 2422-2445.

22. Wang G. 2006. Diversity and biotechnological potential of the sponge-associated microbial consortia. J. Ind. Microbial Biotechnol. 33: 545-551.

23. Herzog B, Overy DP, Haltli B, Kerr RG. 2016. Discovery of keratinases using bacteria isolated from marine environments. Syst. Appl. Microbiol. 39: 49-57. 